\title{
Efektivitas Pengembangan Karakter melalui Fun Garden of Literacy Bagi Anak Usia 7 Tahun
}

\author{
Gusti Yarmi ${ }_{1}{ }_{1}$, Prayuningtyas Angger Wardhani ${ }^{2}$ \\ Pendidikan Guru Sekolah Dasar, Universitas Negeri Jakarta \\ Pendidikan Guru Sekolah Dasar, Universitas Negeri Jakarta \\ DOI: $\underline{10.31004 / \text { obsesi.v4i2.492 }}$
}

\begin{abstract}
Abstrak
Untuk meningkatkan budaya literasi, dibutuhkan model pembelajaran Literasi yang menyenangkan. Penelitian ini bertujuan untuk menguji efektivitas mengembangkan konsep Fun Garden of Literacy yang ramah bagi siswa anak usia 7 tahun. Melalui Fun Garden of Literacy digunakan untuk mengembangan literasi siswa. Penelitian ini menggunakan metode penelitian eksperimental dengan desain pretest-posttest. Sampel dalam penelitian ini berjumlah 100 siswa. Penentuan sampel menggunakan simple random sampling. Temuan perhitungan menunjukkan bahwa terdapat perbedaan kemampuan literasi siswa sebelum dan setelah diberikan perlakuan dengan memberikan Fun Garden of Literacy. Berdasarkan hasil penelitian menunjukkan bahwa Fun Garden of Literacy efektif dalam meningkatkan keterampilan baca tulis siswa anak usia 7 tahun. Fun Garden of Literacy juga dapat menumbuhkan minat baca anak.
\end{abstract}

Kata Kunci: efektivitas pengembangan literasi; taman baca ramah anak; anak usia 7 tahun.

\begin{abstract}
To improve literacy culture, it requires a fun Literacy learning model. This study aims to test the effectiveness of developing a Fun Garden of Literacy concept that is friendly to elementary school students. Through the Literacy Fun Garden or child-friendly reading, the garden can be representative for the development of student literacy. This study uses an experimental research method with the only one village pretest-posttest design. The sample in this study amounted to 100 students. The determination of the sample used the simple random sampling. The data collection techniquesare the tests and observations. The data analysis technique is descriptive statistics and t-test (t-test). The calculation findings show that the result of $t$ is 4.53 with a significance level of 0.002 , which is smaller than 0.05 . The results showed there were differences in the test results before and after being applied a childfriendly reading garden treatment. Based on the results of the study showed that childfriendly reading garden are effective in improving literacy skills of elementary school students. A child-friendly reading garden can foster children's interest in reading.
\end{abstract}

Keywords: effectiveness of literacy development; child-friendly reading parks; 7 year olds.

Copyright (c) 2020 Gusti Yarmi , Prayuningtyas Angger Wardhani

$\triangle$ Corresponding author:

Email Address : gyarmi@unj.ac.id (Jakarta, Indonesia)

Received 4 March 2020, Accepted 22 March 2020, Published 6 April 2020 


\section{PENDAHULUAN}

Pendidikan karakter saat ini adalah masalah utama pendidikan. Selain menjadi bagian dari proses pembentukan moral anak-anak bangsa, pendidikan karakter juga diharapkan menjadi fondasi utama keberhasilan Indonesia Emas pada tahun 2025. Pendidikan karakter didefinisikan sebagai pendekatan yang terencana dan sistematis. Elemen kurikulum tersembunyi yang diadakan di sekolah adalah nilai-nilai, kepercayaan, sikap, dan norma-norma dan nilai-nilai yang merupakan bagian penting dari fungsi sekolah (Çubukçu, 2012). Nilai-nilai karakter dapat diintegrasikan tidak hanya di dalam kelas tetapi juga di dalam budaya sekolah. Beberapa guru tidak terbiasa mengintegrasikan nilai-nilai ini ke dalam budaya (Marini, 2017b, 2017a).

Pakar pendidikan juga memberikan peringatan dini tentang perlunya pendidikan karakter di sekolah (Suyitno, 2019). Peringatan itu disampaikan berdasarkan gejolak untuk melihat realitas kehidupan yang mengindikasikan penurunan moral. Menurunnya mentalitas kolektif masyarakat telah mempengaruhi jatuhnya otoritas sebagai suatu bangsa dalam pandangan bangsa-bangsa lain. Terbukti bahwa dalam banyak hal, orang Indonesia tidak dapat tampil di kancah internasional dengan kepala tegak. Pengembangan karakter sejak usia anak usia 7 tahun dalam menumbuhkan budaya karakter nasional adalah kebutuhan mendesak bagi Indonesia (Anggraini, 2016). Organisasi Pendidikan, Ilmu Pengetahuan dan Kebudayaan PBB (UNESCO) pada 2012 menyatakan bahwa indeks minat baca di Indonesia baru mencapai $0,001 \%$. Berbagai penelitian yang meneliti tokoh-tokoh tersebut adalah(Almerico, 2014; Budsankom et al., 2015; Lintner, 2011; Siregar et al., 2018; Street et al., 2013; Temiz, 2019; Wardhani et al., 2018; Yolcu, 2018; Zurqoni et al., 2018)

Menerapkan karakter sejak usia anak usia 7 tahun adalah gerakan terbaik yang akan menghasilkan kebiasaan (Fatimah Azzahra, 2019). Ada perkembangan berkelanjutan dari gerakan spontan dan refleks ke kebiasaan yang diperoleh, dan dari kebiasaan itu menjadi kecerdasan. Analoginya adalah bahwa anak-anak usia anak usia 7 tahun adalah tunas yang akan tumbuh menjadi pohon yang kokoh, sehingga penguatan karakter harus diterapkan sejak usia anak usia 7 tahun, sehingga penguatan karakter tidak hanya slogan, tetapi sikap yang melekat pada setiap siswa akan terus berlanjut untuk mewarnai kehidupan siswa sepanjang zaman. Dalam menciptakan generasi emas yang dapat membangun bangsa, karakter yang baik menjadi kebutuhan untuk mempersiapkan putra dan putri terbaik bangsa yang akan menjadi pemegang tongkat di masa depan.

Di Indonesia, pendidikan karakter adalah masalah utama pada 2012 hingga hari ini. Integrasi antara ketiganya akan menciptakan bentuk / tatanan terintegrasi yang mengarah pada proses pembentukan karakter. Pendidikan karakter sebagai "kesopanan, keterbukaan pikiran, kompromi, dan toleransi terhadap keanekaragaman." Ini adalah gagasan pendidikan karakter yang terletak dalam penelitian ini (Berkowitz \& Bier, 2004; Lintner, 2011; Nuraeni et al., 2019; Ramdhani et al., 2019). Pendidikan di sekolah perlu diberi satu pengalaman dan pembelajaran yang mencakup aspek pengetahuan, perasaan, dan tindakan. Pengembangan karakter di Indonesia perlu ditanggapi dengan serius karena pengaruh era globalisasi (Studies \& Bilgiler, 2018).

Tindakan yang dihasilkan adalah perwujudan dari proses pengembangan pengetahuan (kognitif) melalui pertimbangan perasaan. Secara implisit, konsep pemikiran dapat diambil bahwa proses pendidikan yang mengarah pada pembelajaran (baik kurikuler, ekstra kurikuler, dan ko-kurikuler) tidak dapat dipisahkan satu sama lain yang melibatkan semua aspek; kognitif, afektif, dan psikomotor. Ketiga aspek tersebut adalah integrasi yang tidak dapat dipisahkan satu sama lain. Dalam sumber lain, Lickona menyatakan bahwa karakter itu sendiri memiliki tiga elemen yang memiliki hubungan kuat antara ketiganya dengan moral, termasuk; (1) pengetahuan moral, (2) perasaan moral, (3) perilaku moral (Thomas Lickona, 1991). Pengetahuan moral berarti perlunya pengetahuan moral bagi individu untuk mengetahui moral yang baik. Perasaan moral berarti pengetahuan moral yang dimiliki oleh seorang individu akan diterima ke dalam suatu pengertian, dan 
kemudian, pada akhirnya, itu menjadi perilaku moral yang ada dalam diri seorang individu. Semuanya merupakan komponen pembentukan karakter secara terintegrasi.

Salah satu upaya dalam mengembangkan nilai-nilai karakter adalah dengan melaksanakan proses pembelajaran tingkat tinggi (HOTS) yang memberikan tantangan untuk memotivasi rasa ingin tahu dan belajar lebih jauh dengan menjadi kreatif dan inovatif, bertahan dan mewujudkan potensi diri dan merangsang semangat kompetitif. Dengan dorongan, motivasi, strategi mengajar guru dengan pembelajaran aktif, kreatif, akan dapat meningkatkan hasil belajar yang tercermin dalam perilaku, prestasi tinggi, kreativitas, produktivitas, dan tanggung jawab. Hasil penelitian Cheung menunjukkan bahwa kontribusi program pendidikan karakter terhadap kompetensi anak sangat besar, terutama kompetensi sosial. Sedangkan dalam penerapan pendidikan karakter tidak mudah bagi guru (Education \& Education, 2019). Penelitian Yunis menunjukkan bahwa guru mengalami kesulitan dalam merencanakan, mengimplementasikan, dan mengevaluasi nilai-nilai pendidikan siswa sehubungan dengan hasil pembelajaran, konten, bahan pembelajaran, kegiatan dan metode, dan mereka menawarkan beberapa solusi untuk mereka (Şahinkayasi \& Kelleci, 2013).

Menanam karakter dapat dilakukan dengan berbagai cara. Studi lain oleh Chou, menyimpulkan bahwa pendidikan karakter dapat memperdalam ikatan antara orang tua dan anak-anak, serta pengaruh yang signifikan dari Budaya Karakter anak-anak prasekolah, dan juga, dukungan dan perancah orang tua prasekolah dalam mendongeng, bermain, musik dan seni pada anak-anak mereka (Lintner, 2011). Anak-anak memainkan faktor penting dalam hubungan orangtua-anak dari anak-anak prasekolah (Şahinkayasi \& Kelleci, 2013; Shih-Wei Chou \& Chien-Hung Liu, 2005). Berdasarkan uraian di atas tujuan penelitian ini adalah melakukan menguji efektivitas mengembangkan konsep Fun Garden of Literacy yang ramah bagi siswa anak usia 7 tahun.

\section{METODOLOGI}

Penelitian ini menggunakan penelitian eksperimental dengan desain penelitian pretest-posttest one group. Penelitian ini adalah penelitian eksperimen semu. Para peneliti tidak memiliki fleksibilitas untuk memanipulasi subjek yang berarti bahwa kelompok acak biasanya digunakan sebagai dasar untuk membentuk kelompok perlakuan dan kontrol. Desain penelitian yang digunakan dalam penelitian ini adalah "One-Post-Test Group Design", yaitu desain penelitian yang memiliki pretest sebelum dirawat dan posttest setelah dirawat. Dengan demikian, dapat diketahui lebih akurat karena dapat dibandingkan dengan diadakan sebelum diberikan perawatan. Tujuan dari penelitian ini adalah untuk mengetahui efektivitas model konsep Fun Garden of Literacy pada siswa usia 7 tahun. Populasi dalam penelitian ini adalah siswa Anak usia 7 tahun Negeri. Teknik pengambilan sampel yang digunakan dalam penelitian ini adalah sampling jenuh yang melibatkan 120 siswa di anak usia 7 tahun Indonesia. Prosedur untuk melakukan penelitian ini termasuk desain yaitu (1) Menentukan sampel penelitian yang akan digunakan (2) Memberikan Pretest untuk menentukan kemampuan literasi siswa di anak usia 7 tahun. (3) Memberikan perlakuan Konsep Fun Garden of Literacy kepada siswa usia 7 tahun. Berikut adalah bagan penelitian One-Post-Test Group Design :

\begin{tabular}{|ccl|}
\hline $\mathrm{O}_{1}$ & $\mathrm{X}$ & $\mathrm{O}_{2}$ \\
Pretest & Perlakuan & Posttest \\
\hline
\end{tabular}

\section{Gambar. 2 Desain Penelitian}

Teknik pengumpulan data yang digunakan adalah tes. Tes diberikan untuk melihat sejauh mana siswa dapat menggunakan pengetahuan yang telah mereka bangun untuk memecahkan masalah. Instrumen yang digunakan dalam penelitian ini adalah tes dalam 
bentuk pertanyaan termasuk pretest dan post-test. Teknik analisis data yang digunakan adalah statistik deskriptif dan uji-t. Tujuan dari uji-t adalah untuk mengetahui hipotesis dalam penelitian ini, yaitu untuk mengetahui apakah ada perbedaan pretest dan postest. Data dalam penelitian ini dikelola dengan bantuan alat penghitungan statistik, aplikasi SPSS versi 22.

\section{HASIL DAN PEMBAHASAN}

Penelitian ini bertujuan untuk mengetahui efektivitas Model Pembelajaran Fun Garden of Literacy pada siswa anak usia 7 tahun. Hasil penelitian dapat dijelaskan sebagai berikut :

Tabel 1. Hasil Pre test dan Post Test

\begin{tabular}{ccc}
\hline & \multicolumn{2}{c}{ Treatment } \\
& Pretest & Postest \\
\hline $\mathrm{N}$ & 100 & 100 \\
Rata-rata & 63.42 & 81.97 \\
Std. Deviasi & 9.713 & 7.222 \\
Std. Error Mean & 971 & 722 \\
\hline
\end{tabular}

Berdasarkan perhitungan pada tabel 1 di atas, menunjukkan bahwa skor rata-rata sebelum menggunakan model Fun Garden of Literacy adalah 63,42 dan setelah diberikan perlakuan mendapat skor rata-rata 81,97. Hasil tersebut menunjukkan bahwa ada perbedaan deskriptif hasil rata-rata literasi awal sebelum dan sesudah menggunakan model Fun Garden of Literacy. Setelah hasil perbandingan antara pretes dan postes diperoleh, hasil selanjutnya adalah korelasi antara pretes dan postes sebagai berikut:

Tabel 2. Hasil Perhitungan Korelasi

\begin{tabular}{|l|l|l|l|l|}
\hline \multicolumn{2}{|l|}{} & N & Correlation & Sig. \\
\hline Pair 1 & $\begin{array}{l}\text { Pre-test \& } \\
\text { Post test }\end{array}$ & 100 & .608 & .000 \\
\hline
\end{tabular}

Tabel di atas menunjukkan bahwa koefisien korelasi skor model Fun Garden of Literacy sebelum dan sesudah dengan nilai 0,608 dengan angka sig, atau nilai $p=0,00050,05$ atau tidak signifikan. Berikut ini adalah Paired Sample korelasi yang ditunjukkan pada tabel 3 di bawah ini :

Table 3. Hasil Paired Sample korelasi

\begin{tabular}{|c|c|c|c|c|c|c|c|c|c|}
\hline & & \multicolumn{5}{|c|}{ Paired Differences } & \multirow{3}{*}{$\mathrm{t}$} & \multirow{3}{*}{ Df } & \multirow[b]{2}{*}{$\begin{array}{l}\text { Sig. } \\
(2- \\
\text { tailed })\end{array}$} \\
\hline & & \multirow[t]{2}{*}{ Mean } & \multirow[t]{2}{*}{$\begin{array}{l}\text { Std. } \\
\text { Deviation }\end{array}$} & \multirow[t]{2}{*}{$\begin{array}{l}\text { Std. Error } \\
\text { Mean }\end{array}$} & \multicolumn{2}{|c|}{$\begin{array}{l}\text { 95\% Confidence } \\
\text { Interval of the } \\
\text { Difference }\end{array}$} & & & \\
\hline & & & & & Lower & Upper & & & \\
\hline Pair 1 & $\begin{array}{l}\text { Pre-test - } \\
\text { Post-test }\end{array}$ & -22.550 & 8.711 & .871 & -20.279 & -16.821 & $\begin{array}{l}- \\
19.294\end{array}$ & 119 & .000 \\
\hline
\end{tabular}

Tabel 3 di atas menunjukkan perbedaan rata-rata $=-22.550$ yang berarti bahwa kemampuan melek huruf mendapat skor setelah dan sebelum menggunakan fun garden literacy. Skor ini menunjukkan bahwa model literasi taman menyenangkan positif digunakan. Kemampuan baca tulis lebih tinggi dari sebelum perawatan. Dengan demikian, 
dapat disimpulkan bahwa ada perbedaan yang signifikan antara hasil sebelum menggunakan model literasi taman yang menyenangkan.

Berdasarkan hasil penelitian, rata-rata sebelum menggunakan model taman menyenangkan yang diperoleh 63,42 dan setelah diberi perawatan, itu meningkatkan skor rata-rata 84,7. Skor statistik adalah $\mathrm{t}=-19,294$ dengan $\mathrm{db} 99$ dan angka yang signifikan. atau p-value $0,000<0,05$. Data yang diperoleh di atas menunjukkan bahwa fun garden literacy adalah salah satu model literacy yang dapat digunakan untuk meningkatkan keterampilan literasi. Untuk menumbuhkan minat anak dalam membaca dan menulis $25 \%$ dipengaruhi oleh keterampilan literasi yang memberikan kontribusi signifikan (Carroll et al., 2018). Dalam mengembangkan keterampilan membaca, guru harus memiliki pengetahuan tentang konsep keaksaraan dan proses serta fase pengembangan keaksaraan (Risko \& Reid, 2019). Hasil penelitian yang meneliti program keaksaraan yang dikembangkan dilakukan oleh beberapa ahli (Clasen, 2017).

Penelitian yang dilakukan menunjukkan bahwa taman belajar memberikan pengalaman otentik dan mencapai hasil akademik positif dalam pembelajaran anak usia 7 tahun (Valentine et al., 2016). Hasil penelitian menunjukkan bahwa taman sekolah memiliki pengaruh positif terhadap pembelajaran. Taman sekolah dapat menjadi cara yang menarik dan efektif untuk melibatkan anak-anak dengan pembelajaran, tetapi ada perbedaan antara guru yang ingin menggunakan taman dalam pengajaran mereka (Passy, 2012). Hasil penelitian terkait dengan taman sekolah yang mendukung pembelajaran (Hrncirik et al., 2017; Mccarty, 2013). Di bawah ini adalah gambar taman bacaan yang dikembangkan oleh peneliti

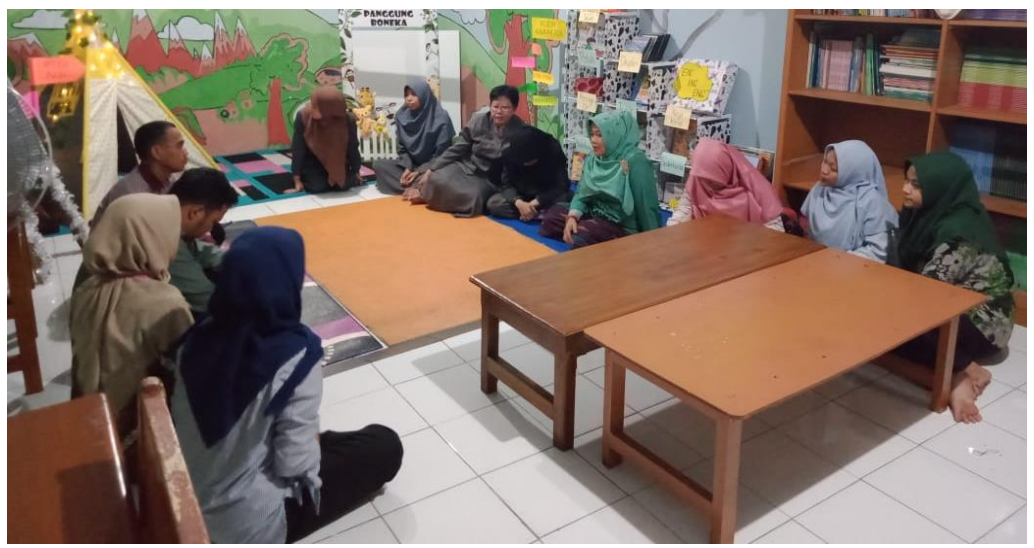

Gambar 1. Taman Bacaan Ramah Anak

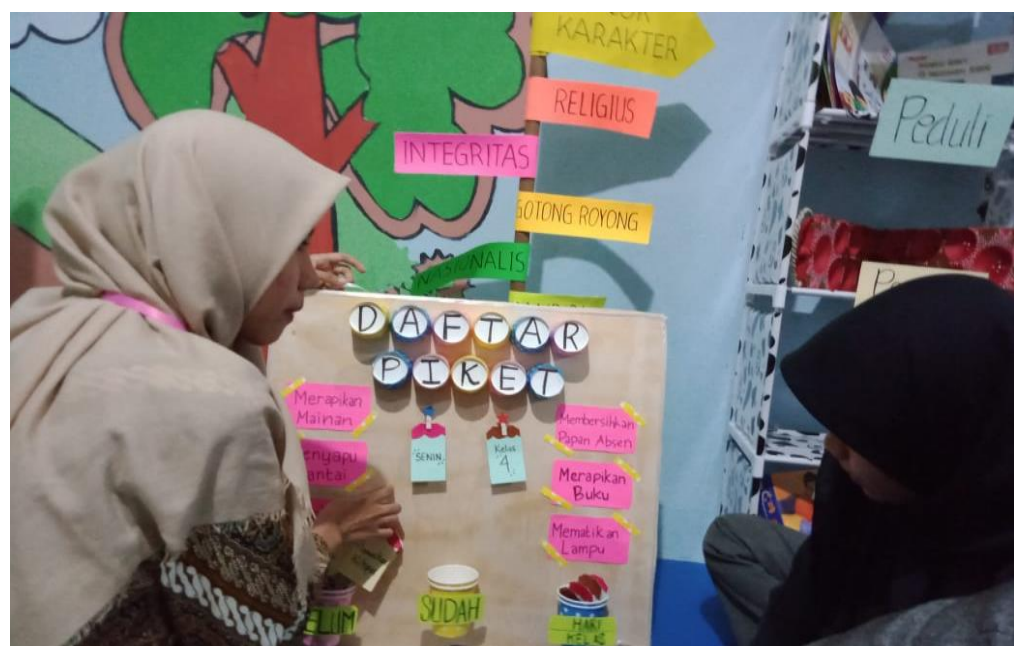

Gambar 2. Salah satu media taman bacaan ramah anak 
Hasil penelitian menunjukkan bahwa dengan adanya taman bacaan ramah anak dapat memotivasi siswa untuk membaca karena ketersediaan buku bacaan yang sesuai perkembangan anak. Selanjutnya taman bacaan ini merupakan wadah eksplorasi guru dalam menciptakan kegiatan-kegiatan berkaitan dengan literasi sebagai sumber belajar, tempat untuk berkarya bagi siswa, meningkatkan emosional bulding dengan praktik-praktik baik literasi di taman baca. ruang membaca yang nyaman, ruang untuk meningkatkan kreativitas berkarya, guru mampu mengasah kemampuan siswa dalam apresiasi sastra melalui taman bacaan.

Salah satu tujuan dari penelitian ini adalah untuk mengembangkan literasi sekolah melalui taman bacaan yang ramah anak. Taman adalah salah satu cara untuk belajar tentang dunia dan diri Anda sendiri (Mccarty, 2013). Penelitian yang dilakukan menunjukkan bahwa taman belajar memberikan pengalaman otentik dan mencapai hasil akademik positif dalam pembelajaran anak usia 7 tahun (Valentine et al., 2016). Hasil penelitian menunjukkan bahwa taman sekolah memiliki pengaruh positif terhadap pembelajaran. Penelitian ini menghubungkan antara memori bekerja dan kemampuan membaca. Memori yang digunakan bekerja untuk membaca (Shin et al., 2018).

\section{SIMPULAN}

Pemerintah telah mengembangkan program gerakan literasi sekolah. Gerakan ini dibuat untuk membudayakan literasi di sekolah. Penerapan taman bacaan ramah anak dalam pengembangan literasi memberikan pengalaman yang berbeda dengan mengembagkan berbagai media yang bervariasi yang belum dikembangkan sebelumnya di sekolah. Hasil penelitian menunjukkan terdapat perbedaan kemampuan literasi sebelum dan sesudah pemberian taman bacaan ramah anak. Dengan adanya taman bacaan ramah anak semakin tertarik untuk membaca serta tes menunjukkan pemberian taman bacaan mendapatkan nilai lebih tinggi.

\section{UCAPAN TERIMAKASIH}

Terimakasih kami ucapkan kepada pihak- pihak yang berperan pada penelitian. Terima kasih kami ucapkan kepada civitas akademika Program Studi Pendidikan Guru Anak usia 7 tahun Fakultas Ilmu Pendidikan Universitas Negeri Jakarta serta Anak usia 7 tahun di wilayah Jakarta Selatan yang telah memberikan izin untuk melaksanakan kegiatan penelitian ini. Ucapan terima kasih juga disampaikan kepada tim editor Jurnal Obsesi yang telah memberikan saran, kritik, dan rekomendasi untuk perbaikan artikel ini.

\section{DAFTAR PUSTAKA}

Almerico, G. M. (2014). Building character through literacy with children's literature. Research in Higher Education Journal Volume 26, 26, 1-13.

Anggraini, P. (2016). The Implementation of Character Education Model Based on Empowerment Theatre for Primary School Students. 7(1), 26-29.

Berkowitz, M. W., \& Bier, M. C. (2004). Research Based Character Education. Annals of the American Academy of Political and Social Science, 591, 72-85. https://doi.org/10.1177/0002716203260082

Budsankom, P., Sawangboon, T., \& Damrongpanit, S. (2015). Factors affecting higher order thinking skills of students: A meta-analytic structural equation modeling study. 10(19), 2639-2652. https:// doi.org/10.5897/ERR2015.

Carroll, J. M., Holliman, A. J., Weir, F., \& Baroody, A. E. (2018). Literacy interest, home literacy environment and emergent literacy skills in preschoolers. 00(00), 1-12. https:// doi.org/10.1111/1467-9817.12255

Clasen, L. E. (2017). BookFun - 'There's more to it than reading a book' - Implementing a Danish early literacy programme that supports professionalism, language development and social 
inclusion. 1. https:/ / doi.org/10.1177/1468798416638405

Çubukçu, Z. (2012). The Effect of Hidden Curriculum on Character Education Process of Primary School Students *. 12(2), 1526-1534.

Education, S. W., \& Education, S. W. (2019). Idealism, Altruism, Career Orientation, And Emotional Exhaustion Among Social Work Undergraduates Author (s ): Steven Sek-yum Ngai and Chau-kiu Cheung Source: Journal of Social Work Education, Vol . 45, No . 1 ( WINTER 2009 ), pp . 105-121 Publishe. 45(1), 105-121.

Fatimah Azzahra. (2019). Pentingnya Penanaman Pendidikan Karakter Sejak Dini di Lingkungan Keluarga.

Kompas. https:// www.kompasiana.com/moh20286/5c2d15c0aeebe13b463d7a80/pentingnyapenanaman-pendidikan-karakter-sejak-dini-di-lingkungan-keluarga-dalamperspektif-tafsir-tarbawi

Hrncirik, L., Lake, M., Smith, S. R., \& Y, M. K. (2017). Tools of the Trade Using the Cultivating Learning with School Gardens Curriculum in Burundi, Africa. 55(4).

Lintner, T. (2011). Using “Exceptional" Children's Literature to Promote Character Education in Elementary Social Studies Classrooms. The Social Studies, 102(5), 200-203. https:/ / doi.org/10.1080/00377996.2010.550955

Marini, A. (2017a). Character Building Through Teaching Learning Process : Lesson In Indonesia. 73(5), 177-182.

Marini, A. (2017b). Integration of Character Values in School Culture at Elementary. 06(05), 21-32.

Mccarty, J. (2013). REAL School Gardens Program: Learning Gardens and Teacher Training to Improve Student Engagement and Academic Performance in Low-Performing Elementary Schools. 4(2).

Nuraeni, L., Andrisyah, A., \& Nurunnisa, R. (2019). Efektivitas Program Sekolah Ramah Anak dalam Meningkatkan Karakter Anak Usia Dini. Jurnal Obsesi : Jurnal Pendidikan Anak Usia Dini, 4(1), 20. https:// doi.org/10.31004/obsesi.v4i1.204

Passy, R. (2012). Education 3-13 : International Journal of Primary, Elementary and Early Years Education School gardens: teaching and learning outside the front door. January 2015, 3741. https:// doi.org/10.1080/03004279.2011.636371

Ramdhani, S., Yuliastri, N. A., Sari, S. D., \& Hasriah, S. (2019). Penanaman Nilai-Nilai Karakter melalui Kegiatan Storytelling dengan Menggunakan Cerita Rakyat Sasak pada Anak Usia Dini. Jurnal Obsesi: Jurnal Pendidikan Anak Usia Dini, 3(1), 153. https:// doi.org/10.31004/obsesi.v3i1.108

Risko, V. J., \& Reid, L. (2019). What Really Matters for Literacy Teacher Preparation? 72(4), 423429. https:/ / doi.org/10.1002/ trtr.1769

Şahinkayasi, Y., \& Kelleci, Ö. (2013). Elementary School Teachers' Views on Values Education. Procedia - Social and Behavioral Sciences, 93, 116-120. https:// doi.org/10.1016/j.sbspro.2013.09.162

Shih-Wei Chou, \& Chien-Hung Liu. (2005). Learning Effectiveness in Web-Based TechnologyMediated Virtual Learning Environment. 3a-3a. https://doi.org/10.1109/hicss.2005.385

Shin, J., Dronjic, V., \& Park, B. (2018). The Interplay Between Working Memory and Background Knowledge in L2 Reading Comprehension. 0(0), 1-28. https:/ / doi.org/10.1002/ tesq.482

Siregar, Y. E. Y., S, Z. M., W, P. A., Rachmadtullah, R., \& Pohan, N. (2018). Self Regulation, Emotional Intelligence With Character Building In Elementary School. 251(Acec), 315-318. https:// doi.org/10.2991/acec-18.2018.72

Street, M., Thambusamy, R., \& Elier, A. A. (2013). From the Shoot. November 2014, 37-41. https:/ / doi.org/10.1080/00094056.2013.852408

Studies, S., \& Bilgiler, S. (2018). Managing School Based on Character Building in The Context of Religious School Culture (Case in Indonesia) Arita Marini 1, Desy Safitri 2 \& Iskandar Muda 3. 9(4), 274-294.

Suyitno, H. (2019). Integration of Character Valuesin Teaching-Learning Process of Mathematics at Elementary School of Japan. 12(3), 781-794. 
Temiz, N. (2019). Full Length Research Paper A lesson plan model for character education in primary education. 14(4), 130-139. https:// doi.org/10.5897/ERR2018.3616

Thomas Lickona. (1991). Educating For Character: How Our School Can Teach Respect and Responsibility. Bantam Books.

Valentine, K., Rummel, S., Selmer, S., Luna, M., \& Rye, J. (2016). How can we best use our school garden space? Exploring the concepts of area and perimeter in an authentic learning context. 21(4), 3-10.

Wardhani, P. A., S, Z. M., Rachmadtullah, R., \& Siregar, Y. E. Y. (2018). Moral Literacy and Social Climate with Perception Teacher's Character Education in Elementary School. 251(Acec), 301-304. https:/ / doi.org/10.2991/acec-18.2018.69

Yolcu, E. (2018). T Eachers' Qualities and Self - Efficacy Perceptions. 11(3), 35-48. https://doi.org/10.24193/adn.11.3-4.3.36

Zurqoni, Retnawati, H., Arlinwibowo, J., \& Apino, E. (2018). Strategy and implementation of character education in senior high schools and vocational high schools. Journal of Social Studies Education Research, 9(3), 370-397. https:// doi.org/10.17499/jsser.01008 